\title{
Semiárido piauiense: expansão da cajucultura e transformações no território
}

\author{
Piauí state/region (Brazil) semi-arid: expansion and \\ transformation of cashew cultivation in the territory
}

\section{Piauiense semiarid: expansión y transformación del caso en el territorio}

\author{
Paulo Gustavo de Alencar ${ }^{1}$ \\ Universidade Federal do Piauí, Brasil \\ Giovana Mira de Espindola \\ Universidade Federal do Piauí, Brasil \\ Antonio Cardoso Façanha ${ }^{3}$ \\ Universidade Federal do Piauí, Brasil \\ Maria de Nazaré Antão de Alencar ${ }^{4}$ \\ Unversidade Regional do Cariri, Brasil
}

1 Engenheiro Agrônomo. Especialização em Geoprocessamento. Mestrado em Desenvolvimento e Meio Ambiente, Universidad Federal de Piauí, Brasil. Servidor do Instituto Nacional de Colonização e Reforma Agrária. E-mail: pgalencar@yahoo.com.br. iD https://orcid.org/0000-0002-7860-6374.

2 Engenheira Cartógrafa. Mestrado e Doutorado em Sensoriamento Remoto. Profa. Dra. do Centro de Tecnologia e do Programa de Pós-Graduação em Desenvolvimento e Meio Ambiente, Universidade Federal do Piauí. E-mail: giovanamira@ufpi.edu.br. (iD https://orcid.org/0000-0003-2691-8496.

3 Licenciatura plena em Geografia. Mestrado e doutorado em Geografia. Prof. Dr. do Departamento de Geografia e do Programa de Pós-Graduação em Geografia e de Desenvolvimento e Meio Ambiente da Universidade Federal do Piauí. E-mail: facanha@ufpi.edu.br. (iD https://orcid.org/0000-0002-1658-1407.

4 Licenciatura Plena em Geografia. Especialização em Geografia e Meio Ambiente. Especialização em Gestão e Educação Ambiental. Professora das redes estaduais do Ceará e Piauí. E-mail: mnazarealencar@ hotmail.com. (iD https//orcid.org/0000-0002-9931-4856. 
Paulo Gustavo de Alencar - Giovana Mira de Espíndola Antonio Cardoso Façanha - Maria de Nazaré Antão de Alencar Piauiense semiarid: expansión y transformación del caso en el territorio

\begin{abstract}
Resumo
O presente artigo objetiva analisar alguns fatores que tem contribuído para as transformações territoriais no Semiárido a partir da expansão agrícola da cajucultura para o município de Pio IX. A pesquisa baseou-se em revisão bibliográfica, entrevistas, observações de campo e análise de imagens de satélite. A abordagem de desenvolvimento territorial tem sido usada na elaboração de planos de desenvolvimento para o Semiárido piauiense. As lutas, conflitos sociais e negociações resultaram na criação de projetos de assentamentos rurais na região da cajucultura, que também foram beneficiados pelo declínio da cajucultura empresarial. A cajucultura familiar assumiu o protaganismo na reorganização da cajucultura no território, favorecidas também pelas novas organizações sociais e políticas resutantes da organziação dos trabalhadores sem terra na busca pela implementação de ações de reforma agrária. As ações do estado desconsideram organização da base produtiva, além da dimensão ambiental. Os diversos planos de desenvolvimento apontam caminhos, mas são pouco efetivos no desencadeamento de ações voltadas para o desenvolvimento territorial.
\end{abstract}

Palavras-chave: Cajucultura; Assentamento rurais; Desenvolvimento Territorial; Semiárido.

\begin{abstract}
This article aims to analyze some factors that have contributed to the territorial transformations in the semi-arid climate region of the state of Piauí, Brazil, due to the farming expansion of cashew (Anacardium occidentale L.) plantation in the municipality of Pio IX. The present research was based on literature review, interviews, field observations, and satellite image analysis. A territorial development approach has been used to implement development plans for the semi-arid Piauí. Struggles, agrarian conflicts and negotiations has contributed to the creation of rural settlement projects within a region traditionally inclined to cashew production; settlements creation also benefited from the decline in cashew agribusiness. Family farming cashew assumed a leading role in the restructuring of the cashew production sector that took place within this territory, this new order was also favored by the new social and political organizations created by landless workers in order to implement the agrarian reform. Government actions seem to disregard the level of organization exhibited by the cashew productive sector, and besides of being indifferent to related environmental issues. Various development plans has showed some solutions, however, these are not very effective in triggering actions aimed at territorial development.
\end{abstract}

Keywords: Cashew plantation; Rural settlements; Territorial development; Semi-arid.

\title{
Resumen
}

Este artículo tiene como objetivo analizar algunos factores que han contribuido a las transformaciones territoriales en el Semiárido, debido a la expansión agrícola de la cajucultura, al municipio de Pio IX. La investigación se basó en la revisión de la literatura, entrevistas, observaciones de campo y análisis de imágenes de satélite. El enfoque de desarrollo territorial se ha utilizado en el desarrollo de planes de desarrollo, para el semiárido de Piauí. Las luchas, los conflictos sociales y las negociaciones, dieron como resultado la creación de proyectos de asentamiento rural en la región del anacardo, que también se beneficiaron del declive de la cultura empresarial del anacardo. El anacardo familiar, asumió el liderazgo en la reorganización del anacardo en el territorio, favorecido también por las nuevas organizaciones sociales y políticas resultantes de la organización de los trabajadores sin tierra, en la búsqueda de la implementación de acciones de reforma agraria. Las acciones del estado desconocen la organización de la base productiva, además de la dimensión ambiental. Los distintos planes de desarrollo apuntan a caminos, pero no son muy efectivos para desencadenar acciones orientadas al desarrollo territorial.

Palabras clave: Cajucultura; Asentamientos rurales; Desarrollo territorial; Semi árido. 
Paulo Gustavo de Alencar - Giovana Mira de Espíndola -

Antonio Cardoso Façanha - Maria de Nazaré Antão de Alencar

Semiárido piauiense: expansão da cajucultura e transformações no território

\section{Introdução}

O processo de modernização conseradora no campo brasileiro marcou a abertura de novas fronteiras agrícolas apoiadas na expansão dos latifíndios e na agricultura tecnificada, caracterizada pelo uso de operações mecanizaadas e uso intensivo de insumos. No Estado do Piauí, as regiões foram ocupadas por diferentes culturas: enquanto a soja tem dominado as extensas chapadas dos cerrados piauienses, no semiárido a cajucultura empresarial foi a responsável pela abertura de extensas áreas, embora não tenha sido o cultivo pioneiro nas chapadas do semiárido.

A cajucultura empresarial teve participação decisiva no processo de mobilidade de pessoas para a ocupação das chapadas do semiárido ns décadas de 1970 e 1980, principalmente em municípios do Território do Vale do Rio Guaribas, como é o caso de Pio IX, que ainda na atualidade mantêm o status de maior área plantada e maior produtor de caju e castanha do Piauí. Entretanto, enquanto a monocultura praticada nos cerrados continuou o seu processo de expansão, a cajucultura empresarial no semiárido entrou em declínio, e a agricultura familiar assumiu o protagonismo no desenvolvimento dos pomares de caju.

Já na década de 2000 o poder executivo passa a adotar a perspectiva do desenvolvimento territorial como horizonte para a elaboração de instrumentos e propostas de planejamento. O estado do Piauí propõe uma nova divisão territorial para o planejamento das ações do Estado, e assim, o "Projeto Cenários Regionais do Piauí", elaborado pelo governo do estado do Piauí em 2003, como uma proposta de planejamento para o desenvolvimento sustentável, e o Plano de Ação para o Desenvolvimento Integrado da Bacia do Parnaíba (PLANAP), elaborado pela CODEVASF servem de base para a formalização da política de Territórios de Desenvolvimento.

A cajucultura foi uma das atividades apontadas no plano de desenvolvimento territorial como essenciais para o desenvolvimento do Território do Vale do rio Guaribas (CODEVASF, 2006) e a estratégia de recuperação adotada pautou-se no fortalecimento da agricultura familiar pelo apoio ao cooperativismo visando a recuperação das cooperativas singulares para o beneficiamento de castanha e a instalação da Central de Cooperativas dos Cajucultores do Estado do Piauí (COCAJUPI) para venda centralizada dos produtos com marca única e com a participação no comércio solidário (Silva, 2011). 
De outra forma, algumas ações desencadeadas nos órgãos fundiários como o Programa de Crédito Fundiário (PCF), o Instituto Nacional de Colonização e Reforma Agrária (INCRA) e o Instituto de Terras do Estado do Piauí, a partir das mobilizações das populações do campo e com o apoio de diversas instituições locais e regionais resultaram no aproveitamento de diversos imóveis deixados ociosos pelos grandes empreendimentos da cajucultura e contribuiram para incorporação de outros ao processo produtivo até então subutilizados.

Assim, é na perspectiva das questões apresentadas que o presente trabalho visa analisar alguns fatores que tem contribuído para as transformações territoriais no Semiárido, tomando como base a expansão agrícola da cajucultura para o município de Pio IX, situado no Estado do Piauí. Analisa-se ainda alguns pontos das propostas de desenvolvimento elaboradas com a perspectiva da sustentabilidade territorial, utilizando para tanto dados de entrevistas, observações de campo, pesquisa bibliográfica e dados de instituições públicas.

\section{A área de estudo}

O município de Pio IX compreende uma área de $1.988,38 \mathrm{~km}^{2}$ e localiza-se no Aglomerado 26 do Território do Vale do Rio Guaribas (Mapa 1), considerando a divisão em territórios de desenvolvimento proposta pelo Governo do Estado do Piauí (CODEVASF, 2006)

Tem como limites os seguintes municípios: ao norte, Pimenteiras, Parambu (CE) e Aiuaba (CE); ao sul, Fronteiras e São Julião; ao leste, Campos Sales (CE); e a oeste, Alagoinha do Piauí, Monsenhor Hipólito e Francisco Santos. 
Paulo Gustavo de Alencar - Giovana Mira de Espíndola -

Antonio Cardoso Façanha - Maria de Nazaré Antão de Alencar

Semiárido piauiense: expansão da cajucultura e transformações no território

Mapa 1. Localização do município de Pio IX - PI (área de estudo).

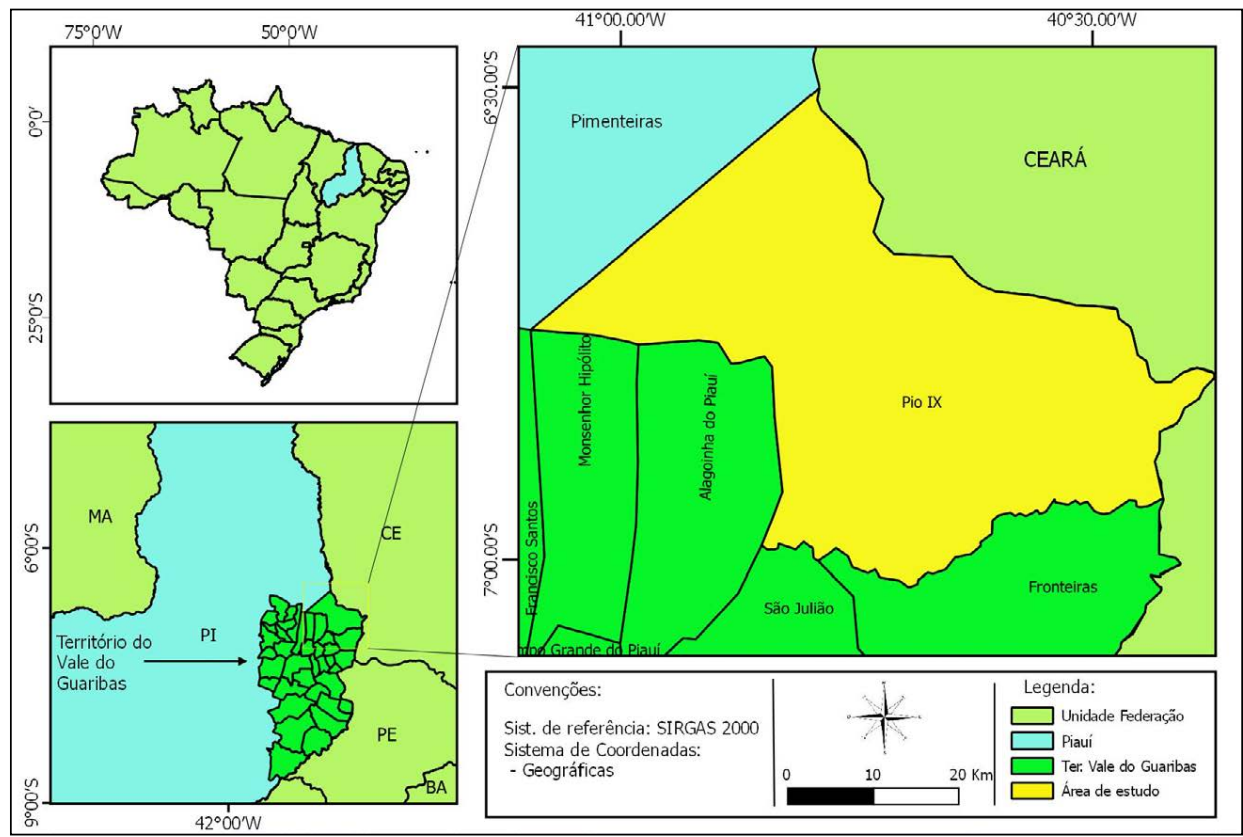

Fonte: elaborado pelos autores a partir de dados do sítio do Instituto Brasileiro de Geografia e Estatística (IBGE).

A sede municipal possui a coordenada geográfica de $06^{\circ} 50^{\prime} 15^{\prime \prime}$ de latitude sul e $40^{\circ} 34^{\prime} 45^{\prime \prime}$ de longitude oeste de Greenwich. Situa-se a uma altitude de 495 metros acima do nível do mar e dista $432 \mathrm{~km}$ de Teresina, capital do Piauí (CPRM, 2004). Segundo dados do Censo 2010, o município possui 6.798 domicílios e uma população total é de 17.693 habitantes, sendo 5.290 residentes na zona urbana e 12.403 na zona rural.

O clima é do tipo tropical semiárido quente e seco, com temperaturas que variam de $18^{\circ} \mathrm{C}$ a $36^{\circ} \mathrm{C}$ e precipitação pluviométrica anual em torno de $700 \mathrm{~mm}$. As chuvas são irregulares e concentradas no período de janeiro a abril, geralmente intercalada com períodos de veranicos (CPRM, 2004).

O município está inserido no bioma Caatinga, com a presença de dois tipos de vegetação associadas aos dois dominínios fisionômicos distintos, inclusive bem diferenciados pela população local: a caatinga hipoxerófila associada as áreas de planalto (chamadas de "serras" pela população local) com altitudes, geralmente, superiores a 550 metros, caracterizada 
pela topografia plana a suave ondulada com o predomínio de Latossolos Amarelos associados à Neossolos Quartzarênicos; a caatinga hiperxerófila associada as áreas de "sertão" (denominação popular local) caracterizadas pela presença de relevo movimentado, de superfícies onduladas entrecortados pela rede de drenagem e fundos de vale, com o predomínio de Neossolos Litólicos e Argissolos Vermelho Amarelos.

De acordo com as entrevistas históricas realizadas na pesquisa de campo, as áreas de planalto ocupadas foram ocupadas à partir da década de 1970 e há absoluto predomínio dos plantios de cajueiro, mas o cultivo de mandioca e do feijão caupi também são importantes, sendo comuns o consórcio entre as três culturas. A apicultura também aparece com atividade de destaque. Ainda de acordo com as informações coletadas em entrevistas, no "sertão" a pecuária é a atividade mais importante, com o destaque para a criação de ovinos, bovinos, suínos e aves, além do cultivo de milho, como atividade de suporte para a pecuária.

\section{As dimensões do desenvolvimento territorial}

Nos últimos anos tem sido comum a utilização da "abordagem" territorial para elaboração de estudos, diagnósticos e planos de desenvolvimentos, seja numa escala nacional, regional ou local, principalmente pelos órgãos estatais coordenados pelo poder executivo federal. Entretanto, para além de modificar as abordagens na formulação dos diversos programas de desenvolvimento rural, é preciso sobretudo expandir o modo de pensar, de analisar e de por em práticas as ações obedecendo os princípios sustentados por essa nova perspectiva.

Assim, Fernandes (2008) destaca que as primeiras publicações com a idéia de desenvolvimento territorial no Brasil começaram na década de 1990, mas a noção de território apenas como espaço físico, como geralmente tem sido feita nos estudos tradicionais, é insuficiente para se pensar o desenvolvimento territorial.

De acordo com Raffestin (1993, p. 153), o território tem amplas vinculações com o espaço, mas são conceitos diferentes. Assim, o território se forma a partir do empoderamento sobre o espaço, tanto do ponto de vista concreto como abstrato. $\mathrm{O}$ território circunscreve o espaço delimitado por um campo de poder e suas relações, ou seja, "exprime a relação que um grupo mantém com uma porção do espaço", mesmo que seus limites não sejam materializados fisicamente. 
Paulo Gustavo de Alencar - Giovana Mira de Espíndola -

Antonio Cardoso Façanha - Maria de Nazaré Antão de Alencar

Semiárido piauiense: expansão da cajucultura e transformações no território

Nesse sentido, Flores e Medeiros (2013), completam que o desenvolvimento como enfoque territorial pressupõe que o território não é apenas um conjunto de fatores físicos e de potencialidades, mas sua constituição abrange fatores imateriais que o configura como uma construção temporal a partir das identidades dos atores, onde a interação homem-espaço gera territorialidades, configurando territórios.

Segundo Saquet (2008), a formação do território se dá pela relação espaço-tempo e seus diversos processos históricos e relacionais, seus fluxos materiais e imateriais, relações de poder, diferenças correlatas e unidades comuns, das identidades do ser humano como ser social e natural, além de suas atividades produtivas. A territorialização é o movimento histórico e relacional resultante dos processos sociais e espaciais que ocorrem dentro e fora do território. Dessa forma, as relações econômicas, políticas e culturais, tanto internas quanto as externas as quais estão relacionadas definem o território.

Na visão de Andrade (1994), o território é gerado e ao mesmo tempo dependente da consciência das pessoas sobre sua participação e dos laços de cooperação, que formariam o sentimento de territorialidade. Ainda segundo o autor, territorialidade seria tanto o que se encontra no território e é influenciado por sua gestão quanto os processos subjetivos de pertencimento das pessoas ao território.

De acordo com Alves (2008), na abordagem territorial torna-se importante o conhecimento de dois modelos de desenvolvimento: o endógeno e o exógeno. No desenvolvimento exógeno a introdução da tecnologia se dá por importação de modelos ou implantação de tecnologias novas. Já o desenvolvimento endógeno abarca as práticas referentes ao enfoque territorial, que remete as empresas e iniciativas da região, e implica na participação dos atores locais em todo o processo, identificando as potencialidades e limitações da região em questão e influindo diretamente nas decisões de desenvolvimento.

Para Wanderley (2011), o enfoque do desenvolvimento rural territorial e sustentável reafirma a existência do espaço rural como específico, com suas particularidades econômicas, sociais, políticas e culturais, e é compreendido como o desenvolvimento das qualidades específicas do rural, onde predominam as relações de proximidade e interconhecimento, e a visão dos habitantes das áreas rurais como sujeitos de direito, onde a cidadania supõe o acesso a bens e serviços já disponíveis para ao restante da sociedade. 
Paulo Gustavo de Alencar - Giovana Mira de Espíndola Antonio Cardoso Façanha - Maria de Nazaré Antão de Alencar Piauiense semiarid: expansión y transformación del caso en el territorio

A concentração fundiária resultante do processo de colonização e agravada por problemas estruturais e pelas grandes secas, tem sido apresentada sistematicamente como um dos principais entraves para o desenvolvimento sustentável do Semiárido e do bioma Caatinga. Dessa forma, Silva (2008) defende que a democratização do acesso à terra, por meio de uma reforma agrária democrática e sustentável, alinhada com os princípios da convivência com a semiaridez, é uma das mais importantes diretrizes para o desenvolvimento sustentável do Semiárido brasileiro.

Abramovay (1999) afirma que o acesso à terra é uma das condições básicas para a inserção social, para o aumento das oportunidades de melhoria de vida, mas que só faz sentido se for acompanhado do acesso a um conjunto de condições que alterem o ambiente institucional local e regional e permitam a revelação dos potenciais com que cada território pode participar do processo de desenvolvimento.

Para Morin (2013), a revitalização das zonas rurais como forma de inverter os fluxos migratórios, encorajar os êxodos urbanos, como uma via fundada no direito à terra dos agricultores sem-terra, tomando como exemplo o caso específico da reforma agrária poderiam ter evitado, em parte, as migrações do Nordeste do Brasil para São Paulo. Entretanto, dado o conservadorismo da formação da nossa sociedade e do Estado brasileiro a implementação da reforma agrária não tem sido um ponto de convergência entre os diversos setores que interagem no rural brasileiro, que tem sido marcado por conflitos da natureza agrária.

De acordo com Fernandes (2008), a relação conflituosa nasce na contradição existente entre a estrutura do sistema capitalista, que produz a concentração de riquezas e a expansão da pobreza e miséria, e o paradoxo do movimento da questão agrária, que destrói, cria e recria relações sociais simultâneas entre capitalismo e campesinato. E nesse sentido, as lutas e disputas pela terra assumem um papel fundamental para reconfiguração do espaço agrário e no território.

Entretanto, Andrade (1994) alerta que os conflitos entre grupos politicamente dominantes e grupos vulneráveis, ao mesmo tempo que expandem o território e consolidam novas territorialidades, ocorre a desterritorialidade dos grupos prejudicados, geralmente de forma violenta como no caso dos choques das diferentes concepções de uso da terra entre os que a enxergam como mercadoria e os se importam com o valor de 
Paulo Gustavo de Alencar - Giovana Mira de Espíndola -

Antonio Cardoso Façanha - Maria de Nazaré Antão de Alencar

Semiárido piauiense: expansão da cajucultura e transformações no território

uso. Dado as constantes disputas de jogo de interesses a da capacidade de imposição dos grupos mais fortes, tanto a categoria território como territorialidade devem ser encaradas como transitórias, já que tudo se acha em constante transformação no tempo e no espaço.

Nessa mesma linha, Roos (2009) afirma que é a partir da luta de classes que o território é transformado e essa transformação reflete na transformação regional, já que a região assim como o próprio território é uma construção social e, portanto, modificável pela ação dos sujeitos na sua relação com o ambiente, mas principalmente que esses sujeitos mantêm entre si. Para Roos (2009), embora os camponeses se organizassem desde um passado distante, é a partir da década de 1980, ao adotarem como principal forma de lutas as ocupações de terra e acampamentos nos latifúndios, que se inicia a principal forma de pressionar o Estado a resolver o problema da posse da terra e a efetivação da reforma agrária.

Do ponto de vista do poder, a sustentabilidade implica o avanço dos processos de gestão participativa que modifique as estruturas dominantes e excludentes do poder político e econômico (Silva, 2008). E para Roos (2009), após a conquista da terra, a luta camponesa não perde sua organização, pois continua dotada de grande conteúdo político entre assentados, que agora passam a se preocupar com a sua reprodução na terra enquanto assentados, o que tem sido luta dos pequenos agricultores frente à ordem expropriatória do sistema capitalista.

Abramovay (2003) tem destacado em seus estudos a noção de capital social como de fundamental importância para o desenvolvimento territorial. Para esse autor, mais importante que vantagens competitivas advindas da potencialidades naturais, de localização ou setoriais, são as relações sociais diretas entre atores, capaz de enriquecer o tecido social de um determinado local, e que permite esses atores se articular e potencializar a utilização do conjunto do ambiente no território, e de convertê-lo numa base para empreendimentos inovadores, e que caracterizam a dimensão territorial do desenvolvimento.

Assim, como observado nas discussões anteriores, a abordagem do desenvolvimento territorial se contrapõe a outras interpretações e apropriações do termo de sustentabilidade, tal qual é apropriado pela corrente econômica neoclássica, que reduz a sustentatibilidade à questão da eficiência econômica e trata a solução dos problemas no território como a uma mera questão técnica. 
Paulo Gustavo de Alencar - Giovana Mira de Espíndola Antonio Cardoso Façanha - Maria de Nazaré Antão de Alencar Piauiense semiarid: expansión y transformación del caso en el territorio

\section{Metodologia}

A metodologia para construção da presente análise levou em conta dados de pesquisa bibliográfica, dados de pesquisas junto ao IBGE, ao Instituto Nacional de Colonização e Reforma Agrária (INCRA), bem como dados preliminares do reconhecimento de paisagem e de entrevistas para o levantamento do histórico da cajucultura no Semiárido piauiense e Diagnóstico dos Sistemas Agrários em pesquisa de mestrado realizada junto a Universidade Federal do Piaú.

A metodologia para realização das entrevistas históricas seguiu as recomendações de Richardson (1999) e a amostragem para definição das entrevistas seguiu o método não probalistico descrito por Sampieri, Collado e Lúcio (2013) para as pesquisas qualitativas. Foram aproveitadas as informações de 05 entrevistas do universo de 55 realizadas.

Para compreensão da dinâmica espacial da cajucultura no município no período de compreendido entre 1985 e 2016 foram realizados 2 mapeamentos de uso e cobertura da terra a partir da classificação de imagens de satélite do Landsat 5 (junho e julho de 1985) e Landsat 8 (agosto de 2016), utilizando-se os mosaicos das cenas órbita/ponto 217/065 e 218/065 (USGS, 1985, 2016). Para o processamento digital de imagens, classificação de imagens e geração de dados temáticos, análise espacial dos dados e produção de mapas temáticos foram utilizados os programas SPRING e QGIS 2.18.24.

Como as imagens do Landsat 8 OLI tem uma resolução radiométrica de 12 bits, diferente das imagens do Landsat 5 TM ( 8 bits), o que confere a primeira uma maior possibilidade de caracterização dos alvos, foram adotados procedimentos diferenciados para tratamento, segmentação e classificação das imagens.

No tratamento das imagens do Landsat $5 \mathrm{TM}$ foram realizadas as etapas de pré-processamento, segmentação e classificação. O pré-processamento, que consiste na correção e preparação das imagens, foi realizado pelo processo de normalização radiométrica, através do método de uniformização das médias e variâncias, conforme metodologia descrita por Santos, Peluzio e Saito (2010). No caso do Landsat 8 OLI as cenas foram segmentadas e classificadas em separado e a fusão das imagens temáticas foi realizada em fase posterior, ou seja, após classificação e validação por meio de edição matricial. 
Paulo Gustavo de Alencar - Giovana Mira de Espíndola -

Antonio Cardoso Façanha - Maria de Nazaré Antão de Alencar

Semiárido piauiense: expansão da cajucultura e transformações no território

A classificação das imagens foi realizada utilizando-se o método de classificação supervisionada por crescimento de região através do algoritmo de Bhattacharya no SPRING com a diferenciação do uso de bandas para os diferentes produtos dos sensores no processo de segmentação e com limiar de aceitação de $99 \%$.

O mapa de relevo que deu suporte a algumas analises foi gerado a partir da sobreposição de uma imagem com classificação de declividade e uma imagem com relevo sombreamento, ambas elaboradas com base em dados do Shuttler Radar Topography Mission - SRTM, resolução de 30 metros (USGS, 2014). Os intervalos para geração das classes de declividade foram construídos de acordo com a classificação de relevo da Embrapa (EMBRAPA, 1979).

\section{Resultados e discussões}

\section{A interface da cajucultura com os assentamentos de reforma agrária}

Para melhor compreensão das mudanças que ocorrem no território faz-se importante também compreender os processos históricos que acontecem numa escala local, levando em conta, entretanto, o contexto dos processos históricos mais gerais que contribuem para a definição das diretrizes das políticas nacionais.

Em balanço sobre os estudos rurais no Brasil, Wanderley (2011) divide didaticamente a história política vinculada ao meio rural em dois subperíodos: o primeiro, que corresponde ao governos militares (1964 1985), marcado pelo grande apoio do Estado à modernização conservadora da agricultura e à expansão capitalista da fronteira econômica versus a repressão ao movimentos sociais e bloqueio da reforma agrária; e o segundo que se confunde com a redemocratização, após 1985, que favoreceu a consolidação dos movimentos sociais e o debate democrático, bem como a emergência de uma pluralidade de sujeitos de direito que reclamam o seu reconhecimento da sociedade brasileira, fortalecidos ainda mais após a constituição de 1988 .

Na década de 1970 inicia-se a implantação dos cultivos de cajueiro no Semiárido piauiense através de duas estratégias distintas. A primeira estratégia foi marcada pelo incentivo aos pequenos produtores por meio da rede de assistência técnica oficial e a oferta de crédito. Já no caso dos 
grandes produtores, o fomento se deu por meio de subsídios e incentivos fiscais obtidos junto a Superintendência de Desenvolvimento do Nordeste (SUDENE), por meio do Fundo de Investimento do Nordeste e Financiamento (FINOR), e de incentivos ao reflorestamento junto ao extinto Instituto Brasileiro de Desenvolvimento Florestal (IBDF).

De acordo com as entrevistas históricas, no município de Pio IX, a cajucultura passa a ocupar as áreas de chapada ("serras") no planalto da Serra Grande. Os pequenos produtores começam a implantar seus pomares no início da década de 1970 em localidades situada em Datas ${ }^{5}$ demarcadas e julgadas pelo poder judiciário, a exemplo das Datas Tamanduá e Povoação (Alencar, 2018, informação verbal ${ }^{6}$; Bezerra, A.V., 2017, informação verbal ${ }^{7}$ ).

Já os grandes projetos de cajucultura empresarial começam a ser implantados no final da década de 1970 e ocupam uma região de grande concentração fundiária localizadas em Datas não demarcadas, com registros de terras irregulares, a exemplo da Data Cova Donga, cujas irregularidades foram diagnosticadas em processos de comprovação de dados cadastrais junto ao INCRA (INCRA, 1995a, 1995b). A conformação da estrutura fundária local é determinante para a localização inicial dos diversos segmentos produtivos da cajucultura: os grandes empreendimentos empresarias nos grandes imóveis rurais das Datas não demarcadas e os agricultores familiares nos pequenos imóveis originados das demarcações judiciais e subdivisões por herança.

Wanderley (2011), resume dessa forma a política de incentivos fiscais:

A política de incentivos fiscais visava ao desenvolvimento da atividade produtiva em áreas escolhidas, especialmente no Nordeste e na Amazônia. Com seu apoio, pessoas jurídicas de todo o país, eram autorizadas a aplicar parte do seu imposto devido em projetos que fossem considerados de interesse para o desenvolvimento regional. $\mathrm{Na}$ verdade, pela ótica dos objetivos declarados, os pífios resultados obtidos com essa política não

5 Datas de Sesmarias ou simplesmente Datas referem-se as concessões de "terras incultas" (do ponto de vista do colonizador) dadas pela coroa portuguesa ou por autoridade revestidas de tal poder a quem se dispusesse em cultivá-las. Eram extensos domínios territoriais concedidas a um único sesmeiro que podiam receber mais de uma sesmaria.

6 Alencar, A. A. De. (2017). Audomi Antão de Alencar: entrevista [mar. 2017]. Entrevistador: Paulo Gustavo de Alencar. Pio IX: UFPI/PRODEMA. 1 arquivo.mp3 (36 min.).

7 Bezerra, A. V. (2017). Antonio Valdenor Bezerra. entrevista [mar. 2017]. Entrevistador: Paulo Gustavo de Alencar. Pio IX: UFPI/PRODEMA. 2 arquivos.mp3 (62 min.). 
Paulo Gustavo de Alencar - Giovana Mira de Espíndola -

Antonio Cardoso Façanha - Maria de Nazaré Antão de Alencar

Semiárido piauiense: expansão da cajucultura e transformações no território

justificam em nada os vultuosos recursos públicos canalizados para atrair grandes empresas para essas regiões ( p. 39).

Assim, a implantação dos grandes empreendimentos da cajucultura, baseados no latifúndio e na empresa capitalista, caracterizam as ações de apoio do estado ao projeto político de modernização conservadora, e o abandono de grande parte desses empreendimentos, conforme se constata-se ao longo do presente artigo, confirmam a pertinência da crítica da autora citada.

A implantação dos grandes empreendimentos da cajucultura empresarial deu início a migrações de trabalhadores os quais se vinculavam, principalmente, como trabalhadores assalariados, morando em agrovilas, como no caso da Fazenda Planalto, ou em residências dispersas, como no caso da Fazenda Capisa e Fazenda São Luís, conforme verificou-se na pesquisa de campo.

Das entrevistas históricas extraiu-se que até a década de 1980 do século passado, a economia rural do municipal girava em torno da integração lavoura de algodão arbóreo - pecuária bovina, comum no semiárido nordestino, quando por problemas estruturais a cultura do algodão entrou em decadência (Almeida, 2017, informação verbal ${ }^{8}$ ). E embora não haja uma relação de casualidade entre o declínio da lavoura algodoeira com a expansão da cajucultura pela concorrência das áreas de produção, já que se adaptam a condições edáficas diferentes, a cajucultura assumiu a lacuna deixada pela lavoura algodoeira no plano socioeconômico (Souto, 2017, informação verbal ${ }^{9}$; Almeida, 2017, informação verbal ${ }^{10}$ ).

Interessam aqui duas questões de natureza local que são definidoras de uma importante interface entre os projetos de assentamento com o arranjo produtivo do caju. A primeira é que a grande concentração fundiária no planalto da Serra Grande, também foco da implantação de grandes projetos e da existência de terras como mera reserva de valor nas Datas não demarcadas, motivam inicialmente a disputa dos movimentos sociais do campo por terra nessa região.

8 Almeida, J. J. (2017). José Joaquim de Almeida: entrevista [mar. 2017]. Entrevistador: Paulo Gustavo de Alencar. Pio IX: UFPI/PRODEMA. 1 arquivo.mp3 (1h 20min.).

9 Souto, J. C. (2017). José Cavalcante Souto: entrevista [mar. 2017]. Entrevistador: Paulo Gustavo de Alencar. Jaicós: UFPI/PRODEMA. 2 arquivos.mp3 (58 min.).

10 Almeida, J. J. (2017). José Joaquim de Almeida: entrevista [mar. 2017]. Entrevistador: Paulo Gustavo de Alencar. Pio IX: UFPI/PRODEMA. 1 arquivo.mp3 (1h 20min.). 
A segunda, mas também de grande importância, é que a expectativa em torno da geração de renda por parte da cajucultura foi um dos fatores que contribuiu para a mobilização dos trabalhadores rurais sem terra da região para os projetos de assentamento nas áreas de planalto. A partir dos anos 1980, a cultura de cajueiro passou a ser explorada de forma mais incisiva pelos agricultores familiares com pequena produção, acarretando migração de famílias do "sertão" para a região de planalto, fomentada pelas expectativas econômicas da nova cultura e o declínio da cultura do algodão, praticada no "sertão".

Os agricultores familiares absorveram parte da tecnologia de produção disseminada pelos grandes grupos empresariais e produzidas pela Embrapa, a exemplo do uso de variedades de cajueiro anão precoce, o plantio de mudas enxertadas e a substituição de copas. Assim, a atividade da cajucultura no âmbito familiar associada a implantação das agroindústrias locais de processamento de pedúnculo foi responsáveis pela dinamização da economia da região nos últimos 20 anos (Alencar, 2018).

Para Façanha (2016), os fluxos intensos de pessoas do Nordeste das décadas de 1960 e 1970 já não se repetiu na década de 1990, resultado de uma reorganização territorial com a construção de novas regiões que promoveu inovações nas dinâmicas urbanas e rurais, gerando novas relações sociais. Mesmo localizando-se na região semiárida, onde o êxodo rural é uma questão emblemática, observa-se que a população do município de Pio IX teve um aumento de 40,79\% entre 1970 e 2010 (IBGE, 2016).

Nos últimos 18 anos, com a implantação de diversos projetos de assentamento da reforma agrária, as áreas de cajueiro anão-precoce foram ampliadas. Dos assentamentos criados no município de Pio IX, dez estão localizados nessa região de interface com a cajucultura (na "serra"), seja total ou parcialmente, e assim, contribuíram para a democratização do acesso à terra, modificando a paisagem, construindo e reconstruindo as relações políticas, sociais e ambientais.

O mapa 2 mostra o mapa de relevo construído a partir da sobreposição de imagem classificada com declividade com uma imagem de sombreamento com o objetivo de diferenciar as áresa de chapada, associadas a fitofisionomia de "serra" (planalto), da fitofisionomia de "sertão". A partir dessa diferenciação do relevo e do gradiente de altitude perceptível pelo efeito tridimensional da sobreposição da imgem sombreada com a classificação de declividade é possível destacar as áreas de planalto das áreas 
Paulo Gustavo de Alencar - Giovana Mira de Espíndola -

Antonio Cardoso Façanha - Maria de Nazaré Antão de Alencar

Semiárido piauiense: expansão da cajucultura e transformações no território

de menor altitude e com relevo movimentado ("sertão"), cuja delimitação aproximada foi representada pela linha roxa pontilhada.

São nessas áreas de "serra" onde localizam-se tanto as áreas da cajucultura quanto a maioria dos assentamentos do Programa Crédito Fundiário (PCF), do INCRA e do Instituto de Terras do Estado do Piauí (INTERPI) vinculados ao município de Pio IX (INCRA, 2016). Como bem representado na figura abaixo nem todos os assentamentos constantes oficialmente no município de Pio IX nos dados dos órgãos gestores de terras estão completamente contidos no polígono do município.

Mapa 2. Relevo do área de estudo e interface dos assentamentos de reforma agrária com as áreas de chapada.

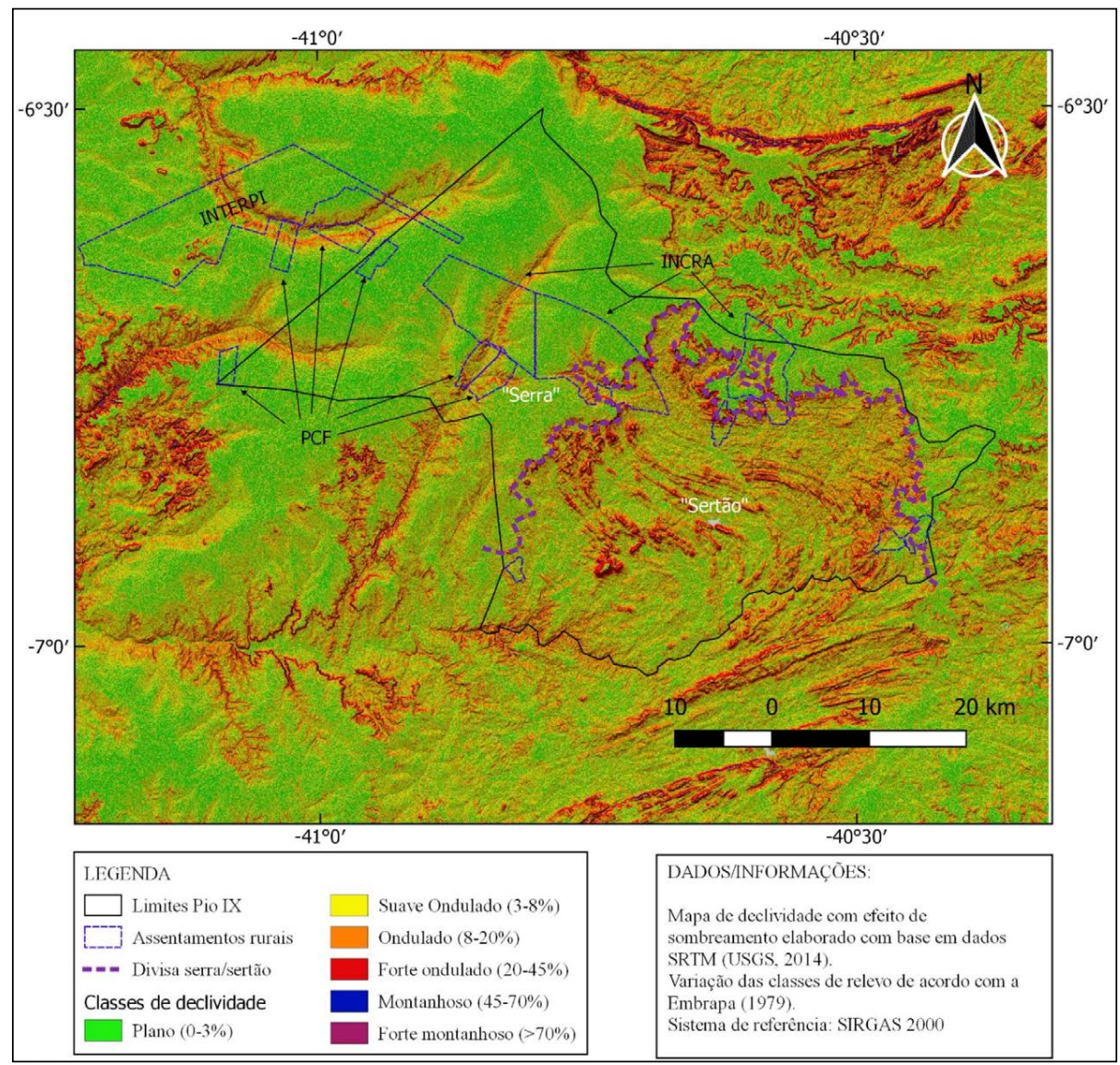

Fonte: elaborado pelos autores com base em dados da SRTM (USGS, 2014) e EMBRAPA (1979). 
Façanha (2016) explica que existem frações do território piauiense que participam do processos globais, são dotados de infra-estrutura técnica e logística que interligam os negócios rurais com o mundo urbano, o que torna as cidades pontos de referência para o rural, surgindo daí uma necessidade para um olhar mais complexo da relação campo - cidade.

Ainda que a cadeia produtiva do caju não possam ser comparadas com a inserção no mercado mundial da maioria das commodities, parte dos seus produtos tem como destino principal o mercado internacional, a exemplo da amêndoa do caju, que tem na exportação para o mercado externo o destino de $90 \%$ da sua produção (FBB, 2010). Assim, essa região da cajucultura pode ser considerada como participe desses processo globais e umas das beneficiárias desse processo de globalização explicado por Façanha (2016).

Outros produtos como o suco de caju tem como mercado outros estados do Nordeste, e a cajuína tem Picos e Teresina como mercados principais, também proporcionando uma inserção nos mercados regionais. Dessa forma, a entrada dessa atividade no região tem contribuído para geração de renda, fixação do homem no campo, e em conjunto com as novas relações sociais criadas, tem influenciado na dinâmica populacional do território.

\section{O contexto fundiário e as lutas camponesas}

No contexto da estrutura fundiária, Pio IX destoa dos demais municípios do Aglomerado 26 do Território Vale do Rio Guaribas, geralmente caracterizados pela inexistência de grandes latifúndios. De acordo com dados do Sistema Nacional de Cadastro Rural (SNCR) do INCRA (INCRA, 2011), até o ano de 2011 existiam 22 grandes propriedades que somavam uma área 115.078,4501 hectares, representando 7,70 \% dos imóveis cadastrados e que ocupavam $43,02 \%$ da área total cadastrada no município. Já os minifúndios eram representados por 2.265 imóveis $(79,30 \%)$ e ocupavam uma área de 58.065,7205 hectares (21,70\%).

Assim, para esse município, as ações de reforma agrária assumem uma importância fundamental para o desenvolvimento territorial e sustentável, eis que grandes porções das terras do planalto da Serra Grande, estão concentradas em grandes propriedades rurais, notadamente nas Datas Cova Donga e Condado. 
Paulo Gustavo de Alencar - Giovana Mira de Espíndola -

Antonio Cardoso Façanha - Maria de Nazaré Antão de Alencar

Semiárido piauiense: expansão da cajucultura e transformações no território

Os grandes imóveis dessas duas Datas foram originaram de registros irregulares de terras ocorridos em meados do século passado, facilitados pelo relações de "compadrio" entre o coronelismo e o judiciário local, corroborando com a afirmação de Wanderley $(2011$, p. 64) de que grande parcela das grandes propriedades no Brasil foram apropriadas de forma ilegal, através de um processo fraudulento comumente chamado de "grilagem de terras". Em muitas dessas terras, a exemplo da Fazenda Esplanada, da empresa CIONE, e da Fazenda Sítios Novos, do Grupo Ernani Viana, foram implantados grandes projetos de caju, a maioria desativados após a redução dos incentivos fiscais ou pela falência dos empreendimentos.

Embora, sempre tenham sido noticiados conflitos de terras nessa vasta região, esses parecem ter sido abrandados de certa forma pelo desinteresse inicial da população local pelas terras de planalto. Esse desinteresse permaneceu até a década de 1980, quando se iniciou o processo de organização de movimentos de camponeses e a luta pela terra, com a formação do Sindicato de Trabalhadores Rurais apoiados pela Comissão Pastoral da Terra, padres e missionários da Igreja Católica. Aliás, a história das lutas no campo no Estado do Piauí tem importante capítulo nesse município onde ocorreram diversas discussões sobre a questão agrária, formando-se lideranças e a organização de trabalhadores rurais vinculados ao Sindicato de Trabalhadores Rurais, sempre apoiado pela Igreja Católica (Borges, 2017, informação verbal ${ }^{11}$ ).

A aquisição de grandes porções de terras pelas empresas vinculadas a atividade da cajucultura geraram conflitos entre posseiros e empresas, como no caso da Fazenda Baixão da Extrema adquirida pela Companhia de Óleos do Nordeste (CIONE), cuja solução foi mediada por acordo e resultou na destinação do citado imóvel pela empresa CIONE aos posseiros históricos (INCRA, 2000a).

As mobilizações em torno desses conflitos desembocaram na realização da primeira romaria da terra da Diocese de Picos ocorrida na região de Cova Donga (margem da BR-020), no ano de 1983, que teve participação de todas as dioceses do Estado do Piauí. O evento ficou marcado como a primeira romaria da terra estadual, e a escolha do local não foi aleatória, contestavam a implantação dos megaprojetos de

11 Borges, G. F. (2017). Gregório Francisco Borges: entrevista [mar. 2017]. Entrevistador: Paulo Gustavo de Alencar. Teresina: UFPI/PRODEMA. 1 arquivo.mp3 (21 min.). 
Paulo Gustavo de Alencar - Giovana Mira de Espíndola Antonio Cardoso Façanha - Maria de Nazaré Antão de Alencar

cajucultura e a expulsão de posseiros para a margem da BR-020 (Borges, 2017, informação verbal ${ }^{12}$ ).

O Sindicado de Trabalhadores Rurais continuou suas ações iniciais voltadas para defesas judiciais da posse de terra dos pequenos posseiros, abertura de processos de desapropriação de grandes latifúndios. Na década seguinte, a luta pela terra foi se arrefecendo, principalmente após a saída de religiosos e missionários que assessoravam no processo de organização. O primeiro assentamento veio a ser criado no ano de 2002, como objeto de negociação através do Programa Crédito Fundiário.

Na década de 2000 dois conflitos de terra originaram a formação de acampamentos como estratégia para pressionar o poder público a efetivar ações de reforma agrária que tiveram importância fundamental para reconfiguração do espaço agrário regional. Ambos foram vinculados aos Movimento dos Trabalhadores Rurais Sem-Terra (MST), mas que tiveram apoio do Sindicato de Trabalhadores Rurais de Pio IX, da Comissão Pastoral da Terra, além de lideranças locais.

Foram palcos de acirradas disputas, resultando na desapropriação do imóvel São Luís, com área superior a 9 mil hectares (INCRA, 2002) e a arrecadação do imóvel Ponta da Serra, com área superior a 17 mil hectares (INCRA, 2000b, 2000c). Ambos resultaram na instalação de assentamentos rurais de reforma agrária, o primeiro sob jurisdição do INCRA e o segundo sob jurisdição do governo do estado do Piauí.

No caso da área arrecadada, embora seu processo de arrecadação tenha sido conduzido pelo governo do estado por questões de competência legal, não houve ação proativa desse ente. A a proposta de transferência do imóvel partiu da empresa proprietária como alternativa para "se livrar do acampamento" e obter como compensação a regularização de outro imóvel com registro de terra também de reconhecida origem irregular (INCRA, 2000b, 2000c).

O acordo firmado pelo governo do estado com autorização da Assembleia Legislativa foi um marco nos processos de arrecadação de terras do Estado do Piauí, já que foi o primeiro que ocorreu dessa forma. No acordo, foram reconhecidos pelo poder público as regularidades dos registros das terras do imóvel Sítio Novo, com 24 mil hectares, enquanto o

12 Borges, G. F. (2017). Gregório Francisco Borges: entrevista [mar. 2017]. Entrevistador: Paulo Gustavo de Alencar. Teresina: UFPI/PRODEMA. 1 arquivo.mp3 (21 min.). 
Paulo Gustavo de Alencar - Giovana Mira de Espíndola -

Antonio Cardoso Façanha - Maria de Nazaré Antão de Alencar

Semiárido piauiense: expansão da cajucultura e transformações no território

estado recebeu em troca o imóvel Ponta da Serra, com área registrada de 26 mil hectares (INTERPI, 2006).

A crise na cajucultura empresarial também contribuiu para a saída de empresas do município, para a regressão dos monocultivos de caju, bem como ajudou a diminuir as tensões em algumas aquisições de terra e, consequentemente facilitou a destinação de terras de grandes projetos empresariais para a reforma agrária no território.

Ainda na década de 2000, alguns imóveis ociosos foram negociadas por agricultores sem-terra com auxílio do Programa de Crédito Fundiário (a exemplo dos assentamentos Santa Fé e Nova Esperança). Assim, somando-se os assentamentos rurais do PCF com os assentamentos rurais instalados nos imóveis desapropriados para fins de reforma agrária pelo Governo Federal e o imóvel arrecadado pelo Governo do Estado, foi possível assentar centenas de trabalhadores rurais sem terra da zona urbana e da zona rural, agricultores sem-terra de outras regiões, posseiros, rendeiros e parceiros, além de trabalhadores rurais desempregados dos grandes projetos de caju em decadência (DEEPASK, 2012; INCRA, 2016).

Nesse sentido, no período de 2002 a 2011 foram criados em Pio IX 14 projetos de assentamento de reforma agrária, sendo 10 vinculados ao Programa Crédito Fundiário, 03 ao INCRA (com 06 núcleos distintos) e 01 ao INTERPI (DEEPASK, 2012; INCRA, 2016).

Eles nascem de contextos específicos que envolvem negociações, conflitos e lutas, enfrentados por organizações sociais distintas, com envolvimento e apoio de movimentos sociais e atores diversos como o Sindicato de Trabalhadores e Trabalhadores Rurais de Pio IX, Comissão Pastoral da Terra - CPT e Igreja Católica (paróquia de Pio IX e diocese de Picos), Movimento dos Trabalhadores Rurais Sem Terra - MST, Federação dos Trabalhadores e Trabalhadoras Rurais na Agricultura do Piauí - FETAG-PI, lideranças políticas, e associações locais.

Para Roos (2009) a luta pela terra e a criação de assentamentos é característica marcante no processo de transformação regional e reconfiguração territorial, pois ocorre um redesenho da paisagem, uma redefinição econômica no nível de produção e da circulação das mercadorias, principalmente no nível local, já que a produção nos assentamentos é maior que no antigo latifúndio. Nesse sentido a criação dos assentamentos não interfere somente na reconfiguração fundiária e econômica do território, 
Paulo Gustavo de Alencar - Giovana Mira de Espíndola Antonio Cardoso Façanha - Maria de Nazaré Antão de Alencar

Piauiense semiarid: expansión y transformación del caso en el territorio

eles modificam além dos aspectos produtivos, constroem novas relações sociais, políticas e ambientais, e dessa forma novas territorialidades.

\section{O planejamento do desenvolvimento territorial}

Entre os exemplos de uso da abordagem territorial constam a política de desenvolvimento territorial da Secretaria de Desenvolvimento Territorial (SDT) do Ministério de Desenvolvimento Agrário (MDA), criada na década de 2000, com a utilização dos "Territórios de Desenvolvimento" como ponto de partida para a implementação da política de desenvolvimento local.

Na elaboração do Plano de Ação para o Desenvolvimento Integrado da Bacia do Parnaíba (PLANAP), instrumento de planejamento para implementação de políticas públicas articuladas no âmbito da Bacia do Rio Parnaíba com foco na sustentabilidade, a noção de território também foi adotada. Nesse plano toma-se como base a proposta de regionalização do Governo do Estado do Piauí para o desenvolvimento sustentável denominada "Projeto Cenários Regionais do Piauí", fundamentada na divisão do estado em Territórios de Desenvolvimento, a partir das indicações do Planos Territoriais da SDT do MDA (CODEVASF, 2006).

Embora a proposta tenha se fundamentado em variáveis ambientais, sociais, econômicas e político-institucionais, ao estabelecer as divisões de macrorregiões e territórios baseada nas características físicas, nas potencialidades de produção e a dinâmica de desenvolvimento (CODEVASF, 2006), pelas próprias contradições do Estado, o viés de "sustentabilidade" tornou-se mero "figurante" nas ações estatais. Dessa forma, esse instrumento de planejamento tem sido mais utilizados para tomadas de decisão na alocação de investimentos do que propriamente para fomentar desenvolvimento territorial.

Assim, a maioria desses planos apontam para necessidade de reformas estruturantes, sobretudo no que diz respeito a reestruturação fundiária, mas que tem sido atrasadas ou negligenciadas pelo Estado, principalmente quanto trata-se do desenvolvimento sustentável do meio rural. As mudanças ocorridas na política de reforma agrária apontam para o contrário e, de acordo com dados do Sistema de Informações de Projetos de Reforma Agrária (SIPRA), o último assentamento criado no Território do Vale do Rio Guaribas se deu em 2011 (INCRA, 2016). Na realidade a questão 
Paulo Gustavo de Alencar - Giovana Mira de Espíndola -

Antonio Cardoso Façanha - Maria de Nazaré Antão de Alencar

Semiárido piauiense: expansão da cajucultura e transformações no território

agrária e ambiental tem sido pouco consideradas na aplicação das políticas públicas para desenvolvimento sustentável do Semiárido.

Silva (2011) destaca que o programa para recuperação da cajucultura com foco no beneficiamento de castanha via cooperativismo foi fomentado a partir do planejamento programa estadual de desenvolvimento sustentável materializado nas discussões do projeto Territórios da Cidadania do Governo Federal, no qual foi definido o apoio as cadeias produtivas de maior relevância para cada região como uma estratégia de desenvolvimento rural sustentável.

O programa financiado pela Fundação Banco do Brasil e outras entidades consistiu em apoiar a instalação de cooperativas singulares nos municípios produtores de castanha bem como recuperar as existentes. Propõe também a criação da Central de Cooperativas dos Cajucultores do Estado do Piauí (COCAJUPI) para qualificar os processos de agroindustrialização e comercialização dos produtos (FBB, 2010).

Entretanto, como observado por Silva (2011), a fragilidade no elo entre as cooperativas singulares, a centralidade das decisões entre os dirigentes da cooperativa central e na passividade dos cooperados e desconsideração do protagonismo dos trabalhadores como estratégia fundamental para planejamento do desenvolvimento, são indicativos de limitação a participação dos agricultores nos processos de decisão.

Em que pese a assertividade da estratégia desenhada para o desenvolvimento da cajucultura piauiense, as informações colhidas em campo e nas revisões bibliográficas atestam que existiram falhas tanto de planejamento quanto de execução nas ações definidas, o que tem dificultado o atingimento dos objetivos. Embora tenham sido reestruturadas diversas cooperativas singulares, a maioria encontra-se paralisadas.

A adesão de apenas 450 produtores em todo o Estado do Piauí a comercialização de castanha via COCAJUPI, conforme informado pelo seu Presidente (Bezerra, 2017, informação verbal ${ }^{13}$ ), a dependência dos cajucultores em relação aos atravessadores na comercialização de castanha e do pedúnculo, conforme Quadros 6 e 11, demonstram que as ações adotadas ainda não foram suficientes para modificar o panorama de organização da cajucultura familiar na região de estudo.

13 Bezerra, J. B (2017). Jocibel Belchior Bezerra: entrevista [mar. 2017]. Entrevistador: Paulo Gustavo de Alencar. Monsenhor Hipólito: UFPI/PRODEMA. 1 arquivo.mp3 (45 min.). 
Como foi observado pelo Presidente da COCAJUPI em entrevista, o principal problema das cooperativas singulares é de gestão, o que aponta para um deficiência no assessoramento técnico na base produtiva. Das nove cooperativas singulares com minifábricas de beneficiamento de castanha instaladas no Estado do Piauí com apoio da Fundação Banco do Brasil, apenas três estão em funcionamento (Bezerra, J. B., 2017, informação verbal ${ }^{14}$ ).

Mesmo diante da importância da cajucultura para geração de trabalho e renda para o município, nas visitas à Secretaria Municipal de Desenvolvimento Rural e ao Instituto de Assistência Técnica e Extensão Rural do Piauí (EMATER/PI), constatou-se que não há profissionais disponíveis para assessoramento técnico aos cajucultores. Na realidade, como se observou ao longo da pesquisa de campo, as ações do governo do estado tem se resumido a distribuição de mudas do cajueiro anão-precoce para recuperação dos pomares.

\section{Análise dos dados espaciais e estatísticos}

O mapa 3 que apresenta o uso e cobertura do município de Pio IX no ano de 1985 reforça a interface das áreas de cultivo com cajueiro com a fitosionomia da "Serra", caracterizadas pela localização no planalto (ver mapa 2), com vegetação de caatinga mais densa (categoria temática representada pelo verde escuro) e solos mais arenosos. Também se pode interpretar que os plantios de cajueiro estão concentrados em monocultivos, conforme observa-se na porção norte extremo oeste do município.

Analisando dados do Censo Agropecuário de 1985, Alencar (2018) constatou que naquele levantamento de dados a área colhida da cajucultura no município de Pio IX foi de 15.000 hectares distribuídos em 524 unidades produtivas. Embora nos dados daquele censo não constasse estratificação de área dos estabelecimentos vinculados a cajucultura, pelo mapeamento de uso e cobertura da terra deduz-se que a cajucultura era ainda dominada pelas grandes empresas, já que é possível observar a concentração dos pomares formando monocultivos. Pelos dados de campo, constatou-se que essas áreas extensivas concentradas na porção norte do município estão

14 Bezerra, J. B. (2017). Jocibel Belchior Bezerra: entrevista [mar. 2017]. Entrevistador: Paulo Gustavo de Alencar. Monsenhor Hipólito: UFPI/PRODEMA. 1 arquivo.mp3 (45 min.). 
Paulo Gustavo de Alencar - Giovana Mira de Espíndola -

Antonio Cardoso Façanha - Maria de Nazaré Antão de Alencar

Semiárido piauiense: expansão da cajucultura e transformações no território

localizadas em grandes propriedades das Datas Cova Donga e Condado, vinculadas a empresas oriundas, sobretudo, do Estado do Ceará.

Os principais grupos empresariais instalados na região foram a Caucaia Industrial Ltda. (CAISA, atual grupo Ernani Viana) e a Companhia de Óleos do Nordeste (CIONE). O grupo CAISA chegou a implantados 21 mil hectares de cajueiro até o ano de 1991 (INCRA, 1995a) e o grupo CIONE implantou 19,8 mil hectares até meados da década de 1990 (INCRA, 1995b).

No ano de 1990, o município teve uma 46.827 hectares de área colhida de cajueiro, mas foi no ano de 1995 que atingiu o ápice, com uma área colhida de 64.570 hectares. Curiosamente, no ano seguinte, em 1996, houve uma queda brusca na área colhida, que passou para 8.697 hectares distribuídos em 803 unidades produtivas, refletindo a crise da cajucultura empresarial. Das 803 unidade produtivas, 732 vinculavam-se ao estrato de área inferior a 100 hectares (91\%), o que representava a importante adesão dos agricultores familiares ao novo cultivo (Alencar, 2018).

Ainda com base no mapa 3 observa-se plantios de cajueiro dispersos na porção centro-oeste do município, que caracterizam o predomínio da cajucultura familiar, presentes sobretudo pelas nas pequenas propriedades rurais das Datas Tamanduá e Povoação.

O dados do Censo Agropecuário 2006 ao mesmo tempo que reforçam a adesão dos agricultores familiares ao cultivo do caju, já que 727 unidades produtivas, do total de 758 unidades, situavam-se no estrato de imóveis rurais abaixo de 100 hectares $(95,91 \%)$. O envolvimento de unidades produtivas envolvidas com a colheita do pedúnculo (caju) passou de 19,92 \% no Censo Agropecuário de 1995/1996 para 52,37\% no Censo Agropecuário de 2006, o que reflete o aproveitamento do caju pela agroindústria recém instalada no local.

De qualquer forma ainda havia uma concentração da produção nos grandes monocultivos, pois 17.481 hectares (de um total de 20.540 hectares) estavam vinculados a imóveis com área superior a 1000 hectares. Por outro lado, 544 unidades estavam contidas no estrato de área inferior a 5 hectares, o que dá indicativos de má distribuição fundiária como um fator limitante para o desenvolvimento da atividade (Alencar, 2018). 
Paulo Gustavo de Alencar - Giovana Mira de Espíndola Antonio Cardoso Façanha - Maria de Nazaré Antão de Alencar

Mapa 3. Mapa de uso e cobertura da terra do município de Pio IX do ano de 1985.

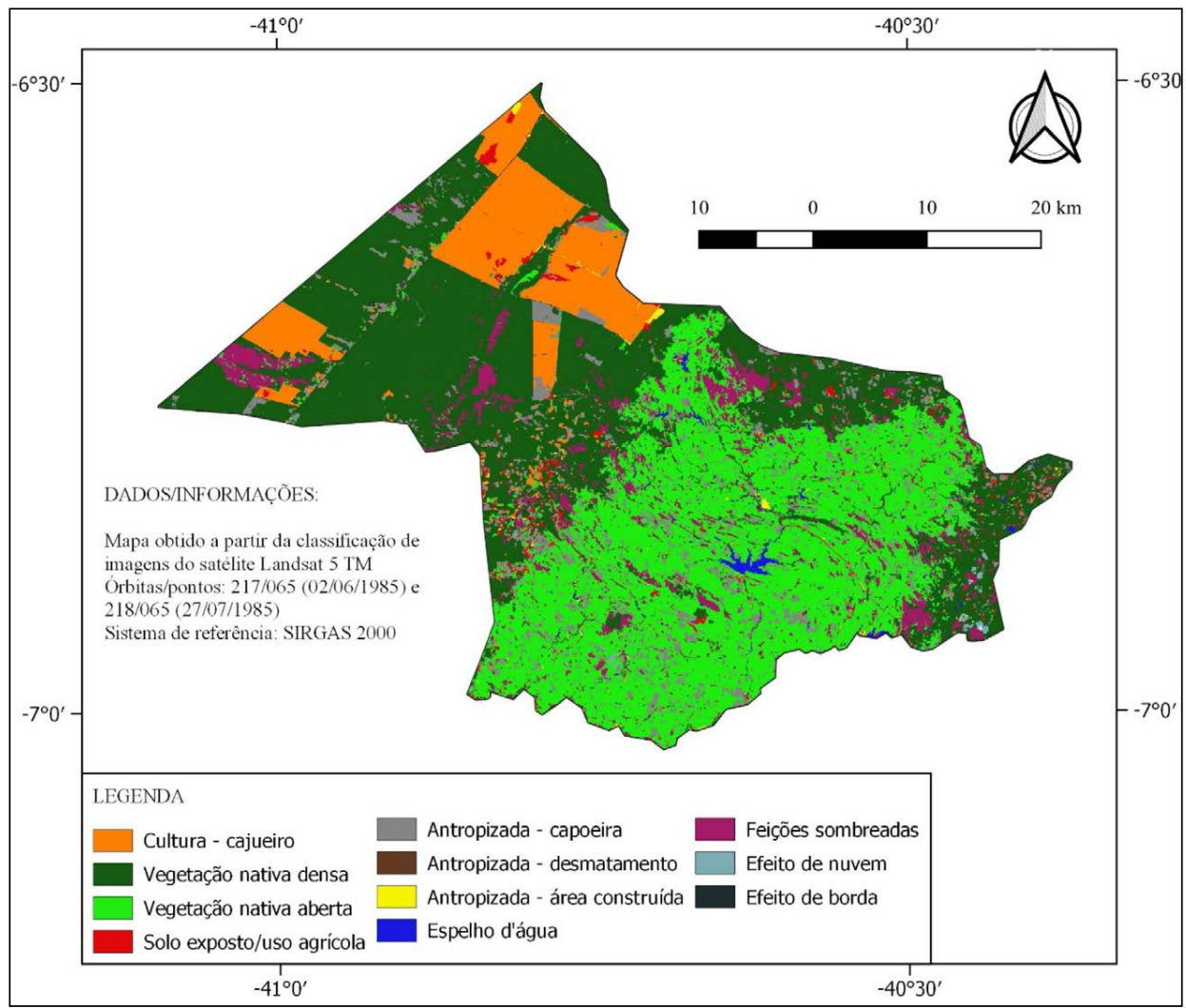

Fonte: elaboração dos autores com base em imagem do Landsat 5 fornecida pelo USGS/NASA (USGS, 1985).

O mapa de uso e cobertura da terra do ano de 2016 (mapa 4) permite interpretar que há uma expansão da área da cajucultura familiar na região centro-oeste, dado o formato entrecortado dos polígonos dos pomares na região imediatamente inferior aos 4 assentamentos rurais mais centrais. Constata-se ainda que ocorreu a introdução da cajucultura nos assentamentos recém-criados entre 2002 e 2011 o que poder ser observado pela categoria temática "cultura - cajueiro" no interior dos 4 polígonos centrais de assentamentos rurais.

De acordo com Leite (1994), após a retirada dos incentivos fiscais e a concorrência da amêndoa de castanha de caju da Índia no mercado 
Paulo Gustavo de Alencar - Giovana Mira de Espíndola -

Antonio Cardoso Façanha - Maria de Nazaré Antão de Alencar

Semiárido piauiense: expansão da cajucultura e transformações no território

internacional uma grave crise assolou a cajucultura empresarial na década de 1990. O mapa 4 caracteriza bem a retração das áreas de cajucultura extensivas das grandes empresas pelo abandono de seus pomares e surgimento da categoria temática "antropizada capoeira" em locais anteriormente ocupados com monocultivos de cajeiro.

Mapa 4. Mapa de uso e cobertura da terra do município de Pio IX do ano de 2016.

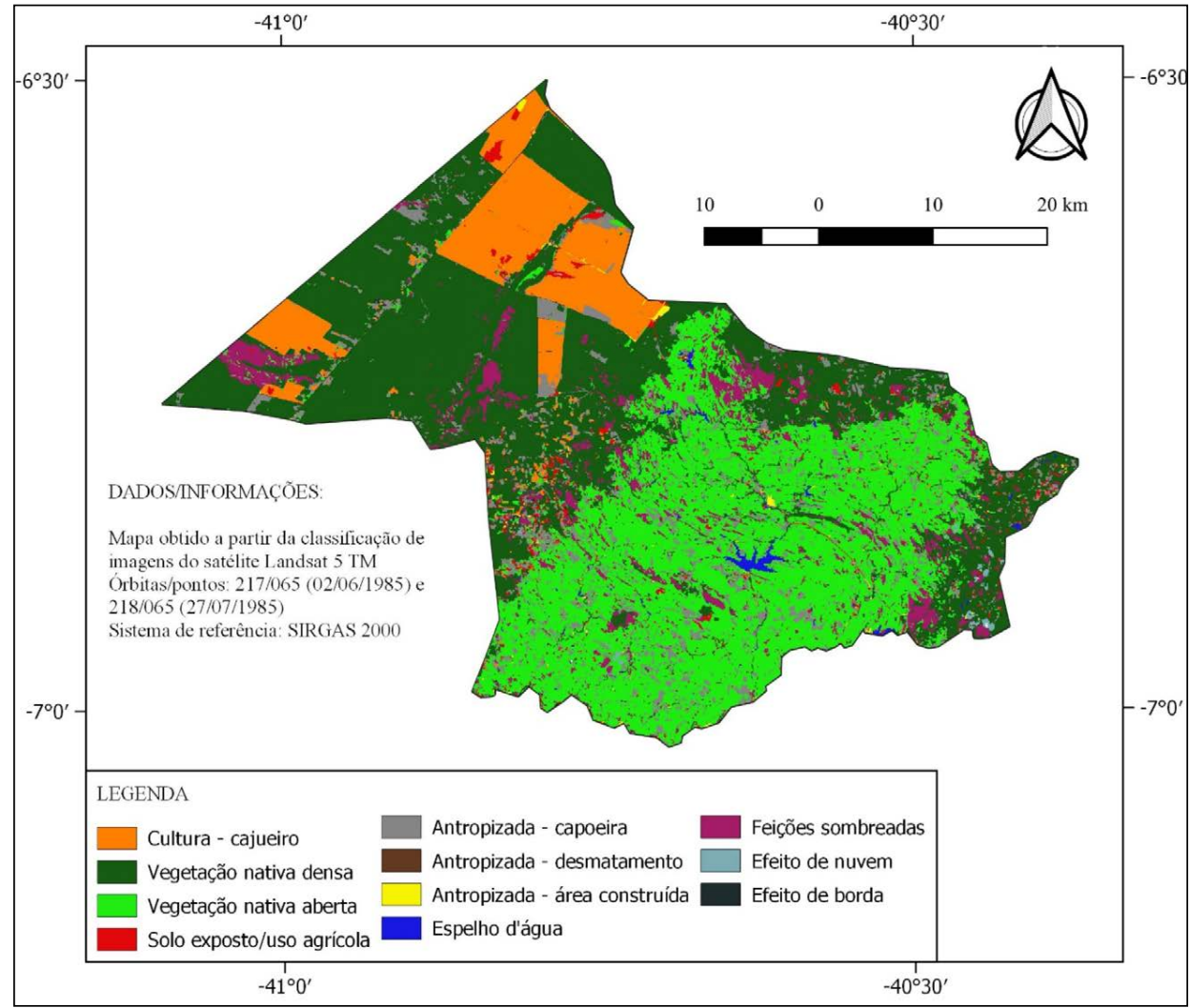

Fonte: elaboração dos autores com base em imagem do Landsat 8 fornecida pelo USGS/NASA (USGS, 2016).

Comparando os mapas 3 e 4 extrai-se que foi a expansão da cajucultura que causou os maiores impactos sobre a Caatinga na área de estudo, notadamente nas áreas de planalto. Inicialmente, as áreas empresariais foram as responsáveis pelas retiradas de grandes porções florestais, mas a expansão da cajucultura familiar também favoreceu a fragmentação da 
Paulo Gustavo de Alencar - Giovana Mira de Espíndola Antonio Cardoso Façanha - Maria de Nazaré Antão de Alencar Piauiense semiarid: expansión y transformación del caso en el territorio

vegetação, principalmente na porção centro-oeste da imagem. A expansão da vegetação de caatinga aberta para as regiões de planalto também, como se observa no mapa 4, deve está relacionada com a mortalidade da vegetação nativa ocasionada pelo longo período de estiagem que assolou a região no período de 2011 a 2016.

No ano de 2015 a área colhida sofreu uma redução para 18.487 hectares, o que pode está relacionado também com o longo período de estiagem que assolou a região. Já no Censo Agropecuário de 2017 observa-se um ligeira recuperação da área colhida que é de 22.918 hectares, mas associada a apenas 650 unidades produtivas o que pode representar ainda os efeitos da estiagem prolongada (Alencar, 2018).

\section{Considerações finais}

A expansão da fronteira agrícola foi decisiva para as alterações no território do município em questão, que se caracterizam por diversos processos territorialização, desterritorialização e reterritolialização, seja pelo declínio de arranjos produtivos, como ocorreu com o binômio algodão pecuária bovina, seja pela introdução da cajucultura.

Com a crise da cajucultura nordestina na década de 1990, a cajucultura empresarial também sofreu um processo de desterritorialização, e a cajucultura familiar em conjunto com a agroindústria de processamento de pedúnculo contribuíram para a revigoração da atividade na região, marcada pelo predomínio dos pequenos plantios de cajueiro anão-precoce e aproveitamento do caju (pedúnculo).

A expansão da cajucultura gerou a expropriação de posseiros, mas resultou também em negociações que desembocaram no reconhecimento de posses, além da geração de empregos diretos na fase inicial. As lutas e conflitos sociais marcaram as disputas e negociações pelas posses e os processos de aquisição de terras, originando os projetos de assentamentos, além de migrações e emigrações. Esses distintos processos tiveram influência tanto na modificação do espaço, quanto nas relações e organizações sociais, políticas e ambientais, algumas das quais ainda em plena construção e reconstrução, que marcam o caráter transitório do território e da territorialidade.

Os processos que apontam para a reconfiguração territorial são resultantes de pressões sociais e políticas que fortaleceram alguns atores locais, notadamente os agricultores familiares e pequenos empresários locais. Nas 
Paulo Gustavo de Alencar - Giovana Mira de Espíndola -

Antonio Cardoso Façanha - Maria de Nazaré Antão de Alencar

Semiárido piauiense: expansão da cajucultura e transformações no território

últimas décadas forjou-se o surgimento de uma nova categoria, os assentados de reforma agrária, que emergiram junto aos novos espaços de reprodução, e organização político-social, os assentamentos rurais de reforma agrária, que por sua vez continuam a promover a reterritorialização.

Pelo que foi discutido até o presente, entende-se que há um capital social em formação a partir da criação dos diversos projetos de assentamentos rurais na região de estudo, da expansão da cajucultura familiar e das agroindústrias locais. Mas, a inexistência em nível local e regional de assessoria técnica que considere as novas relações sociais e suas dimensões territoriais, incluindo aqui a dimensão ambiental, contribui para dificultar a integração das comunidades e assentamentos rurais. Esse deveria ser o principal foco de atuação do poder público nas diversas escalas para contribuir com o desenvolvimento sustentável da região.

Em que pese a existência de diversos planos de desenvolvimento elaborados pelo poder público que consideram no seu arcabouço teórico a abordagem da territorialidade e da sustentabilidade, os entes estatais não agem proativamente. A paralisação das ações de reforma agrária e a desconsideração das ações de reestruturação fundiária para o desenvolvimento do Território do Vale do Guaribas mostram a falta de compromisso do estado com o desenvolvimento do Semiárido piauiense.

As ações do Governo do Estado, restritas e distribuição de mudas de apenas dois tipos de clones de cajueiro para a recuperação dos pomares, tem contribuído para homogeneidade das populações de cajueiro, o que demonstra falta de uma política integrada com base em desenvolvimento territorial, que considere, entre outras, a dimensão ambiental.

\section{Referências}

Abramovay, R. (1999). Agricultura familiar e desenvolvimento territorial. Revista da Associação Brasileira de Reforma Agrária, 28 -29, 49-67.

Abramovay, R. (2003). O futuro da regiões rurais. Porto Alegre: Editora da UFRGS.

Alves, A. F. (2008). Conhecimentos convencionais e sustentáveis: uma visão de redes interconectadas. Desenvolvimento territorial e agroecologia. São Paulo: Expressão Popular. 
Paulo Gustavo de Alencar - Giovana Mira de Espíndola Antonio Cardoso Façanha - Maria de Nazaré Antão de Alencar Piauiense semiarid: expansión y transformación del caso en el territorio

Andrade, M. C. (1994). Territorialidades, desterritorialidades, novas territorialidades: os limites do poder nacional e do poder local. Território: globalização e fragmentação. São Paulo: Editora Hucitec.

Alencar, P. G. (2018). Cajucultura no Semiárido piauiense: sistemas agrários e dinâmica espacial. Dissertação (Mestrado em Desenvolvimento e Meio Ambiente) - Universidade Federal do Piauí, Programa de Desenvolvimento e Meio Ambiente, Teresina.

CODEVASF. (2006). Companhia de Desenvolvimento dos Vales do São Francisco e do Parnaíba. Plano de ação para o desenvolvimento integrado da Bacia do Parnaíba. CODEVASF. Brasília: TDA Desenhos \& Arte Ltda.

CPRM. (2004). Serviço Geológico do Brasil. Projeto cadastro de fontes de abastecimento por água subterrânea, estado do Piauí: diagnóstico do município de Pio IX. Robério Bôto de Aguiar e José Roberto de Carvalho Gomes (Org.). Fortaleza: CPRM.

DEEPASK. (2012). Programa Nacional de Crédito Fundiário: Veja recursos investidos por cidade do Brasil - PIO IX, PI. Crédito Fundiário. Gráficos com dados de Pio IX, PI. Recuperado de: http://www. deepask.com/goes?page=pio-ix/PI-Programa-Nacional-de-CreditoFundiario:-Veja-recursos-investidos-por-cidade-do-Brasil.

EMBRAPA. (1979). Empresa Brasileira De Pesquisa Agropecuária. Serviço Nacional de Levantamento e Conservação de Solos. SNLCS. Súmula da 10. Reunião Técnica de Levantamento de Solos. Rio de Janeiro: EMBRAPA-SNLCS:

Façanha, A. C. (2016). Ensaio sobre a agricultura familiar no território, no rural e nas políticas públicas. In: Piauí, desenvolvimento territorial e escalas de abordagem. Teresina: EDUFPI.

Fernandes, B. M. (2008). Conflitualidade e Desenvolvimento Territorial. In: Luta pela terra, reforma agrária e gestão de conflitos no Brasil. Campinas, SP: Editora da Unicamp.

Flores, S. S. e Medeiros, R. M. V. M. (2013). A dimensão territorial da sustentabilidade. In: Estudos territoriais na ciência geográfica (1 ed.) São Paulo: Outras Expressões.

FBB. (2010). FUNDAÇÃO BANCO DO BRASIL. Fruticultura - Caju: volume 4. Desenvolvimento Regional Sustentável. Série Cadernos de propostas para a atuação em cadeias produtivas. Brasília: Banco do Brasil/IICA. 
Paulo Gustavo de Alencar - Giovana Mira de Espíndola -

Antonio Cardoso Façanha - Maria de Nazaré Antão de Alencar

Semiárido piauiense: expansão da cajucultura e transformações no território

IBGE. (2016). Instituto Brasileiro de Geografia e Estatística. Sistema IBGE de Recuperação Automática - SIDRA. Banco de Dados Agregados População. Tabelas de novembro de 2016. Recuperado de: http://www. sidra.ibge.gov.br/bda/tabela/protabl.asp? $\mathrm{c}=202 \& \mathrm{z}=\mathrm{t} \& \mathrm{o}=25 \& \mathrm{i}=\mathrm{P}$.

INCRA. (1995a). Instituto Nacional de Colonização e Reforma Agrária. Desapropriação por interesse social para fins de reforma agrária do imóvel rural Fazenda Sítio Novo, situada no municipio de Pio IX. Processo $n^{\circ} 21680.001400 / 95-62$. Documentos do processo. Teresina, PI: INCRA/SR-24/PI.

INCRA. (1995b). Instituto Nacional de Colonização e Reforma Agrária. Comprovação de dados cadastrais da Fazenda Esplanada, situada no município de Pio IX. Processo $\mathrm{n}^{\circ}$ 21680.000179/95-43. Documentos do processo. Teresina, PI: INCRA/SR-24/PI.

INCRA. (2000a). Instituto Nacional de Colonização e Reforma Agrária. Comprovação de dados cadastrais da Fazenda Baixão da Direita/ Data Cova Donga (Serra Nova), situada no município de Pio IX. Processo $n^{\circ} 54380.000131 / 00-44$. Documentos do processo. Teresina, PI: INCRA/SR-24/PI.

INCRA. (2000b). Instituto Nacional de Colonização e Reforma Agrária. Comprovação de dados cadastrais da Fazenda Ponta da Serra, situada no município de Pio IX. Processo ${ }^{\circ}$ 54380.000160/00-42. Documentos do processo. Teresina, PI: INCRA/SR-24/PI.

INCRA. (2000c). Instituto Nacional de Colonização e Reforma Agrária. Comprovação de dados cadastrais da Fazenda Sítio Novo, situada no município de Pio IX. Processo $n^{\circ} 54380.000172 / 00-21$. Documentos do processo. Teresina, PI: INCRA/SR-24/PI.

INCRA. (2002). Instituto Nacional de Colonização e Reforma Agrária. Desapropriação por interesse social para fins de reforma agrária do imóvel rural Fazenda São Luís, situada no município de Pio IX. Processo ${ }^{\circ} 54380.001373 / 2002-70$. Documentos do processo. Teresina, PI: INCRA/SR-24/PI, 2002.

INCRA. (2011). Instituto Nacional de Colonização e Reforma Agrária. Situação jurídica dos imóveis rurais, por município no Estado do Piauí. Estrutura_Fundiária_Nov_2011.xls (arquivo). INCRA. Sistema Nacional de Cadastro Rural - SNCR. 
Paulo Gustavo de Alencar - Giovana Mira de Espíndola Antonio Cardoso Façanha - Maria de Nazaré Antão de Alencar

Piauiense semiarid: expansión y transformación del caso en el territorio

INCRA. (2016). Instituto Nacional de Colonização e Reforma Agrária. Relatório de Projetos de Reforma Agrária - Piauí. INCRA. Sistema de Informações de Projetos de Reforma Agrária - SIPRA.

INTERPI. (2006). Instituto de Terras do Estado do Piauí. INTERPI fecha acordo em Pio IX para assentar mais de mil famílias. Portal do Governo do Estado Piaúi.Recuperado de: www.interpi.pi.gov.br/materia.php?id $=80$.

Leite, L. A. de S. (1994). A agroindústria de caju no Brasil: políticas públicas e transformações econômicas. $176 \mathrm{f}$. Tese (Doutorado em Economia) - Universidade Estadual de Campinas, Instituto de Economia, Campinas.

Morin, E. (2013). A via para o futuro da humanidade. Carvalho, E. de A. e Bosco, M. P. (tradução). Rio de Janeiro: Bertrand Brasil.

Raffestin, C. (1993). Por uma geografia do poder. Tradução de Maria Cecília França. Série Temas, v.29, Geografia e Política. São Paulo: Editora Ática.

Richardson, R. J. (1999). Pesquisa social: métodos e técnicas (3 ed).. São Paulo: Atlas.

Roos, D. (2009). Territorialização da luta pela terra e transformações regionais. In: Leituras do conceito de território e de processos espaciais. Saquet, Marcos Aurélio e Souza, Edson Belo Clemente de (Organizadores). São Paulo: Expressão popular.

Santos, A. R. dos, Peluzio, T.M. de O.; Saito, N. S. (2010). SPRING 5.1.2: passo a passo: aplicações práticas. Alegre: F \& M Gráfica.

Sampieri, R.H.; Collado, C. F. e Lucio, M. del P. B. (2013). Metodologia de Pesquisa. Tradução de Daisy Vaz de Moraes (5. ed). Porto Alegre: Penso. Saquet, M. A. (2008). Por uma abordagem territorial. In: Territórios e territorialidades: teorias, processos e conflitos. São Paulo: Expressão Popular: UNESP.

Silva, R. M. A. Da. (2008). Entre o combate à seca e a convivência com o semi-árido: transições paradigmáticas e sustentabilidade do desenvolvimento. Fortaleza: Banco do Nordeste do Brasil.

Silva, M. das M. E. (2011). Associativismo: as cooperativas de caju em Picos, Piaui - COCAJUPI. Dissertação (Mestrado em Serviço Social) - Universidade Federal do Pernambuco, Centro de Ciências Sociais Aplicadas, Picos. 
Paulo Gustavo de Alencar - Giovana Mira de Espíndola -

Antonio Cardoso Façanha - Maria de Nazaré Antão de Alencar

Semiárido piauiense: expansão da cajucultura e transformações no território

USGS. (1985). United States Geological Survey. Landsat 4-5 Mission . Recuperado de: https://earthexplorer.usgs.gov/Landsat/ LandsatColletion2Level-2/Landsat4-5TMC2L2.

USGS. (2014). United States Geological Survey. Shuttler Radar Topography Mission - SRTM, . Recueprado de: https://earthexplorer.usgs. gov/DigitalElevation/SRTM.

USGS. (2016). United States Geological Survey. Landsat 8 Mission, . Recuperado de: https://earthexplorer.usgs.gov/Landsat/ LandsatColletion2Level-2/Landsat8Oli/TIRSC2L2.

Wanderley, M. de N. B. (2011). Um saber necessário: os estudos rurais no Brasil. Campinas, SP: Editora da Unicamp. 
